\title{
Discriminação dos depósitos cenozoicos da parte emersa da Bacia Paraíba (NE, Brasil) por meio de minerais pesados e granulometria
}

\author{
Discrimination of Cenozoic deposits from the onshore portion of the \\ Paraíba Basin (NE, Brazil) using heavy minerals and grain size \\ Felipe Lamus Ochoa ${ }^{1 *}$, Ana Maria Góes ${ }^{2}$, Dilce de Fátima Rossetti ${ }^{3}$, André \\ Oliveira Sawakuchi ${ }^{2}$, Lucas Villela Cassini ${ }^{2}$, José Moacyr Vianna Coutinho ${ }^{4}$
}

\begin{abstract}
RESUMO: Controvérsias na estratigrafia dos depósitos sedimentares expostos na Bacia Paraíba motivaram investigaçóes visando análises de minerais pesados, incluindo morfologias de zircão e turmalina. $\mathrm{O}$ estudo revelou grande similaridade mineralógica entre as unidades aflorantes (Formação Barreiras e Sedimentos Pós-Barreiras I e II), com domínio de zircáo, turmalina, cianita e rutilo. A maioria das amostras da Formação Barreiras é relativamente mais pelítica que as amostras derivadas dos Sedimentos Pós-Barreiras. Entretanto, a similaridade das porcentagens de minerais pesados impossibilitou discriminar essas unidades geológicas por meio somente da composição mineralógica. Refinamento estratigráfico foi obtido por meio de análises morfológicas de zircáo e de turmalina, que foram eficientes na diferenciação das unidades sedimentares estudadas, com aumento de categorias arredondadas em direção aos depósitos mais jovens. Além disso, o aumento progressivo do índice ZTR nesses depósitos, aliado à constância dos valores do índice de proveniência RZ, sugerem que as principais fontes dos depósitos cenozoicos da Bacia Paraíba foram rochas sedimentares preexistentes e, subordinadamente, rochas metamórficas da Zona Transversal da Província Borborema.
\end{abstract}

PALAVRAS CHAVES: minerais pesados; depósitos cenozoicos; Bacia Paraíba; estratigrafia.

\begin{abstract}
Controversies about the stratigraphy of the Cenozoic deposits of the Paraiba Basin outcropping onshore motivated the analysis of the heavy minerals assemblage and the morphology of zircon and tourmaline grains with the purpose of improve the stratigraphic framework of the basin. These studies revealed strong similarity among the heavy mineral assemblage of the outcropping stratigraphical units (Barreiras Formation and Post-Barreiras I and II units), with the predominance of zircon, tourmaline, kyanite and rutile. An improved stratigraphic discrimination was obtained using morphological analysis of zircon and tourmaline grains, with increasing grain roundness towards younger units. Moreover, the fact that the ZTR index increases gradually towards younger units, and that the $R Z$ index remains constant suggests that older sedimentary units and, subordinately, metamorphic rocks from the Transversal Zone of the Borborema Province are the main sources of the studied $C_{e-}$ nozoic sediments.
\end{abstract}

KEYWORDS: heavy minerals; cenozoic deposits; Paraiba Basin; stratigraphy.

\footnotetext{
${ }^{1}$ Corporación Geológica ARES, Bogotá, Colombia.E-mail: flamus@cgares.org

²Departamento de Geologia Sedimentar e Ambiental, Universidade de São Paulo - USP, São Paulo (SP), Brasil. E-mail: goes@igc.usp.br; andreos@usp.br; lucascassini72@gmail.com

${ }^{3}$ Departamento de Sensoriamento Remoto, Instituto Nacional de Pesquisas Espaciais, São José dos Campos (SP), Brasil. E-mail: rossetti@dsr.inpe.br ${ }^{4}$ Departamento de Mineralogia e Geotectônica, Universidade de São Paulo - USP, São Paulo (SP), Brasil. E-mail: limocout@gmail.com

*Autor correspondente

Manuscrito ID: 29872. Receibido em: 19/12/2012. Aprovado em: 27/08/2013.
} 


\section{INTRODUÇÃO}

Os depósitos siliciclásticos aflorantes na parte emersa das bacias marginais do nordeste brasileiro têm recebido múltiplas designaçóes estratigráficas. Diferenças entre mapas geológicos da faixa costeira entre Recife e João Pessoa (Dantas 1982; Santos et al. 2002) têm dificultado o entendimento do preenchimento sedimentar da Bacia Paraíba. Alguns pesquisadores (Rossetti et al. 2007, Rossetti \& Góes 2007) atribuem idade cenozoica à maior parte das unidades sedimentares mapeadas (por exemplo, Formação Barreiras e Sedimentos Pós-Barreiras) na zona costeira emersa, enquanto outros (por exemplo, Beurlen 1967, Brito Neves et al. 2009) consideram essas unidades como mesozoicas (por exemplo, formaçóes Beberibe e Itamaracá). Esse fato está relacionado à aparente similaridade litológica entre as unidades siliciclásticas, ausência de fósseis e elevado grau de intemperismo. Além disso, a ocorrência isolada desses arenitos e a ausência de marcadores estratigráficos importantes, como os carbonatos cretáceos e eocenos das formaçóes Gramame e Maria Farinha, dificultam ainda mais o mapeamento geológico. Por fim, o aspecto endurecido de alguns depósitos pertencentes aos Sedimentos Pós-Barreiras tem levado à atribuição de idade cretácea, embora já tenha sido demonstrado que essa característica, mais do que decorrente da litificação por soterramento, deve-se à ressedimentação por processos sismogênicos contemporâneos à sedimentação (Rossetti et al., 2011a ).

Com objetivo de contribuir para a resoluçáo do problema estratigráfico da Bacia Paraíba, este trabalho apresenta resultados da análise de minerais pesados, já que este método tem sido utilizado com sucesso na correlação estratigráfica de outras unidades sedimentares siliciclásticas (por exemplo, Morton 1991, Mange-Rajetzky 1995, Morton \& Hurst 1995, Morton \& Grant 1998, Svendsen \& Hartley 2002, Mange et al. 2003). As assembleias de minerais pesados podem revelar a proveniência dos sedimentos (Basu 1985, Morton et al. 1991, Mange \& Maurer 1992, Morton \& Hallsworth 1994, Dill 1998). Dada sua capacidade de discriminar depósitos sedimentares com fontes e/ou histórias deposicionais e pós-deposicionais distintas, a análise de minerais pesados tem potencial de auxiliar na diferenciação de unidades sedimentares litologicamente similares, porém depositadas em tempos geologicamente distintos.. A caracterização e a quantificação de minerais pesados das unidades sedimentares aflorantes na zona costeira da Bacia Paraíba podem contribuir na apresentaçáo de critérios que permitam melhorar sua caracterização estratigráfica (Fig. 1).

\section{CONTEXTO GEOLÓGICO}

\section{Província Borborema}

A Província Borborema representa o embasamento da sucessão sedimentar da Bacia Paraíba e ocupa uma extensão de mais de $400.000 \mathrm{~km}^{2}$, confinada entre as províncias São Francisco a sul, Parnaíba a norte, e as bacias marginais a leste. Essa província coincide com a região de Dobramentos Nordeste, desenvolvida no Ciclo Brasiliano, que corresponde a um mosaico de diversos sistemas de dobramentos lineares separados por altos do embasamento relacionados ou não com falhas (Almeida et al.1977). De acordo com a classificação de Van Schmus et al. (2008) e Brito Neves et al. (2000), essa província apresenta seis domínios: Sergipano, Pernambuco-Alagoas, Riacho do Pontal, Transversal, Rio Grande do Norte-Ceará e Médio Coreaú (Fig. 1). Os terrenos metamórficos do Alto Pajeú, Alto Moxotó e Rio Capibaribe, localizados entre as zonas de cisalhamento de Pernambuco e Patos, configuram o Domínio Transversal. A projeçáo dessas zonas de cisalhamento delimita e define a estruturação tectônica da Bacia Paraíba, a qual é subdividida em três sub-bacias, que incluem, de sul para norte: Olinda, Alhandra e Mirirí. Essas sub-bacias são limitadas pela Zona de Cisalhamento de Pernambuco e pelas falhas de Goiana, Itabaiana e Mamanguape (Lima Filho 1998).

\section{Bacia Paraíba}

Foi a última bacia marginal a se formar no final do Cretáceo e seu preenchimento sedimentar não excedeu a $400 \mathrm{~m}$ de espessura, sendo menos espessa que sua vizinha a sul, a Bacia Pernambuco, cujo embasamento alcançou mais de $3.000 \mathrm{~m}$ de profundidade (Lima Filho 1998, Lima Filho \& Souza 2001). No Turoniano-Santoniano, por causa da subsidência na regiáo entre o Lineamento de Pernambuco e o Alto de Touros, iniciou-se a deposiçáo dos sedimentos fluviais da Formação Beberibe (Beurlen 1967, Lima Filho \& Souza 2001, Lima Filho et al. 2006). No Neocampaniano-Eomaastrichtiano, transgressão marinha resultou na deposição da Formação Itamaracá (Kegel 1955, Barbosa et al. 2007). Por meio da correlação com a discordância mesocampaniana registrada na Bacia Portiguar, esses autores inferiram a existência de uma discordância erosiva mesocampaniana entre as formaçóes Beberibe e Itamaracá, (Quadro 1 e Fig. 2). Durante o Neocampaniano, a Bacia Paraíba encontrava-se em franco processo de transgressão que culminou na construção da plataforma carbonática Gramame no Maastrichtiano-Santoniano, sob fase tectônica estável (Lima Filho et al. 2006). Durante o EocenoPaleoceno, regressão marinha foi responsável pela deposição dos sedimentos carbonáticos da Formação Maria 
Farinha, seguida de soerguimento e erosão (Barbosa 2004, 2007). Os depósitos siliclásticos sobrepostos à Formação Maria Farinha foram estudados por diversos pesquisadores (Quadro 1), com destaque para a síntese feita por Beurlen (1967). Esse autor adota as nomenclaturas definidas por Bigarella e Andrade (1964) e Campos e Silva (1968), os quais reconhecem as seguintes unidades estratigráficas: Formação Guararapes (Mioceno), e formações Riacho Môrno, Macaíba e Potengi (Pleistoceno). Para Barbosa et al. (2007), a sucessão siliciclástica posterior à Formação Maria Farinha é denominada de Formação Barreiras, considerada de idade pliocênica. De modo geral, a maior parte dos depósitos da Formação Barreiras é interpretada como fluvial (por exemplo, Bigarella \& Andrade 1964; Mabesoone et al. 1972, Bigarella 1975), porém com parte atribuída a ambientes estuarino (Salim et al. 1975), lagunar ou de planície de maré (Alheiros \& Lima Filho 1991). Os sedimentos costeiros da Formação Barreiras são associados a uma transgressão marinha de caráter global que se estendeu até finais do Mesomioceno (Shimabukuro \& Arai 1999, Arai 2006, Rossetti \& Góes 2009). Posteriormente, a queda do nível do mar e o longo período de quietude tectônica propiciaram que sedimentos previamente depositados fossem expostos ao intemperismo, o que resultou em expressivo paleossolo laterítico (Rossetti 2004). A partir do Pleistoceno, a sedimentação foi retomada em razão de reativaçóes tectônicas ao longo de antigas zonas de cisalhamento (Bezerra et al. 2008). Isso permitiu deposição e preservação de espessa sucessão sedimentar quaternária. A designação informal de "Sedimentos Pós-Barreiras" para essa sucessão quaternária foi proposta por Rossetti et al. (2007), seguindo a subdivisão estratigráfica originalmente proposta para os depósitos da regiāo Norte do Brasil (Sá 1969, Rossetti 2000, Rossetti \& Góes 2001).

\section{MATERIAIS E MÉTODOS}

\section{Estratigrafia}

Observaçôes foram feitas em exposiçóes na parte nordeste da Bacia Paraíba, entre João Pessoa e norte de Goiana, na Sub-bacia Alhandra. Também foram descritos afloramentos na Sub-bacia Mirirí, com vistas à caracterização e correlaçáo das unidades sedimentares que ocorrem sobrepostas ao embasamento cristalino. Foram levantadas seçóes colunares com amostragem representativa dos intervalos estratigráficos expostos em cada ponto estudado. Procurou-se coletar areias e arenitos com, aproximadamente, a mesma granulação para evitar efeitos da segregação hidráulica na assembleia de minerais pesados. Foram coletadas 119 amostras de superfície, das quais 42 pertencem à Formação Barreiras e 77 aos Sedimentos Pós-Barreiras (Fig. 3).

\section{Análise granulométrica}

Foram processadas 119 amostras. Utilizou-se a técnica de pipetagem para estimativa das fraçóes granulométricas nas classes silte e argila (fração menor que 0,063 mm) (Mcmanus 1991). Para análise das fraçóes arenosas (0,063 $\mathrm{mm}$ a $2,00 \mathrm{~mm}$ ), foi utilizada a técnica de peneiramento a seco. Foram calculados as estatísticas diâmetro médio, desvio padrão, assimetria e curtose, por meio do método dos momentos de Pearson, mediante o uso do programa momento4-expansão.xls (Giannini et al. 2007).

\section{Minerais pesados}

A fração granulométrica areia muito fina $(0,063 \mathrm{~mm}$ a $0,125 \mathrm{~mm}$ ) foi selecionada para separação dos minerais pesados mediante a técnica de flutuação e afundamento em líquido denso (bromofórmio $\mathrm{CHBr}_{3}, \rho=2,85 \mathrm{~g} / \mathrm{cm}^{3}$. Os grãos de minerais pesados foram montados em lâminas de vidro com bálsamo do Canadá e identificados ao microscópio de luz polarizada. A quantificação mineralógica foi feita com base no método de contagem por linha (Galehouse 1969), contando-se 100 grãos de minerais pesados translúcidos náo micáceos por lâmina. Inicialmente, foram contados os minerais translúcidos e opacos e depois quantificados os minerais translúcidos não micáceos presentes. Os resultados obtidos representam frequências de ocorrência desses minerais, e aqueles com porcentagem inferior a $1 \%$ foram considerados traços. O cálculo do índice ZTR foi feito por meio da somatória das percentagens de zircão, turmalina e rutilo, advindas da quantificação dos minerais pesados translúcidos. Esse índice indica o grau de maturidade mineralógica dos sedimentos (Hubert 1962). Também foi computado o índice mineralógico RZ (RZi $=100 \times$ rutilo/rutilo+zircão) segundo proposta de Morton \& Hallsworth (1994). A determinação desse índice foi feita por contagem de 100 gráos do par de minerais em questáo, sendo essa contagem independente da quantificação da assembleia de minerais pesados. Esse par de minerais apresenta densidade, estabilidade química e comportamento hidráulico similares, e as variações obtidas denotam modificaçôes na proveniência sedimentar (Morton \& Hallsworth 1994).

Foi utilizada, por último, a técnica de análise de minerais pesados de alta resolução (Mange-Rajetzky 1995, Mange et al. 2005, Mange \& Otvos 2005). Foram selecionados zircão e turmalina com contagens de 100 grãos por mineral, porém, quando o número de grãos não alcançou esse valor, desde que superior a 21 grãos, os dados foram normalizados visando ao tratamento estatístico. O zircão 


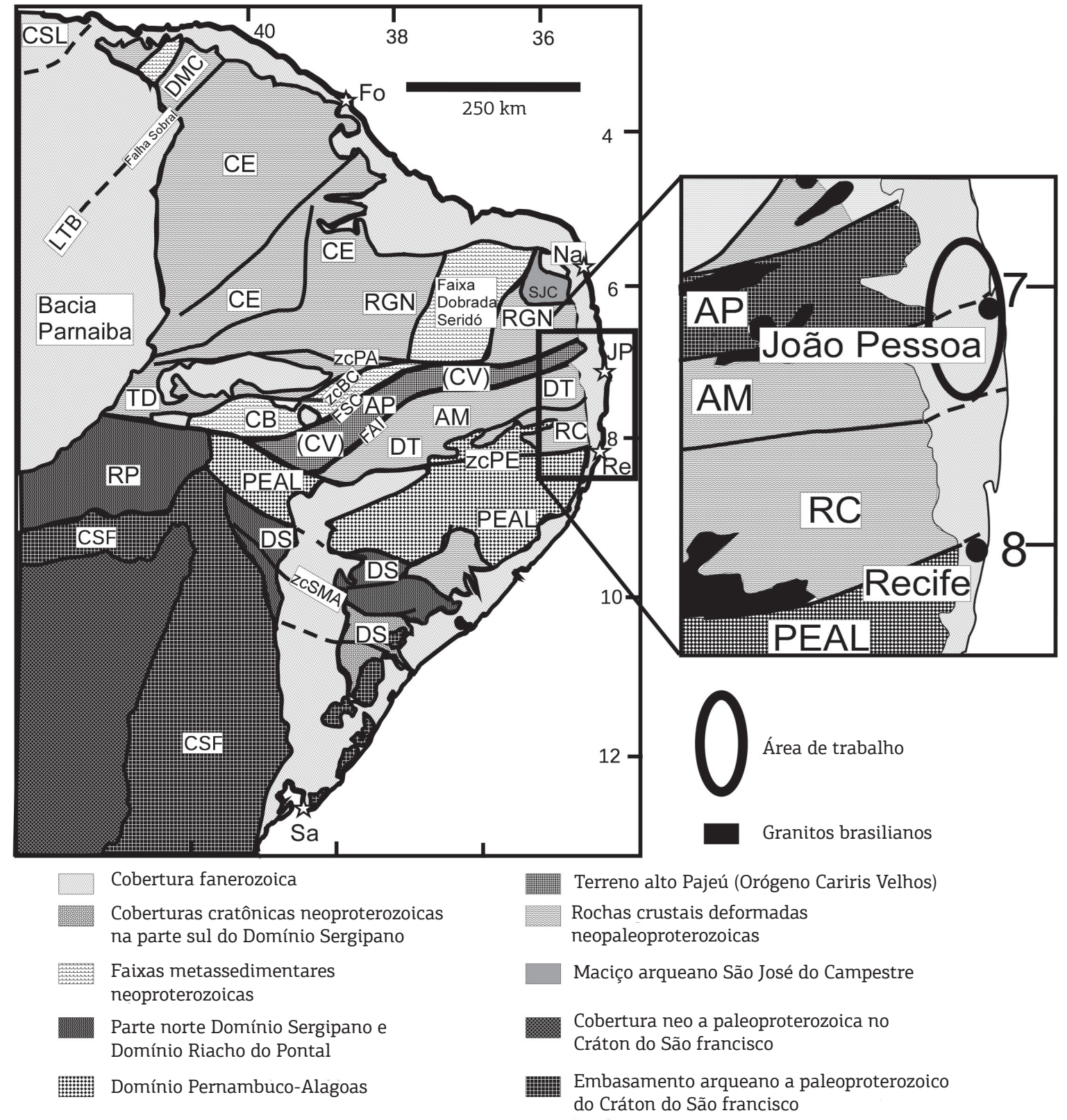

CE: Domínio Ceará; DMC: Domínio Médio Coreaú; PEAL: Domínio Pernambuco-Alagoas; RGN: Domínio Rio Grande do Norte (núcleos arqueanos, São José do Campestre: SJC); RP: Domínio Riacho do Pontal; DS: Domínio Sergipano; CSF: Cráton do São Francisco; CSL: Cráton São Luis; DT: Domínio Transversal (AP: Terreno Alto Pajeú; AM: Terreno Alto Moxoto; CB: Faixa Cachoerinha; CV: Faixa Orogênica Cariris Velhos; RC: Terreno Rio Capibaribe). Zonas de falha e cisalhamento: FAI - Falha Afogados do Ingazeira; zcBC - Zona de Cisalhamento Boqueirão dos Conchos; zcPA - Zona de Cisalhamento Patos; PEsz - Zona de Cisalhamento Pernambuco; FSC - Falha Serra do Caboclo; zcSMA - Zona de Cisalhamento São Miguel do Aleixo; LTB - Lineamento Transbrasiliano. Cidades: Fo - Fortaleza; Na - Natal; JP - João Pessoa; Re - Recife; Sa - Salvador (segundo Van Schmus et al. 2008).

Figura 1. Província Borborema, bacias sedimentares adjacentes e localização da área de estudo

foi subdividido em 7 categorias e a turmalina em 5, cuja escolha baseou-se em formas euédricas e anédricas, sendo estas últimas subdivididas segundo o grau de arredondamento de Powers (1953). O zircâo faz parte do sistema tetragonal, e as formas euédricas mais comuns são prismas bipiramidais (Corfu et al. 2003). A turmalina, em geral, pode apresentar três hábitos; prismas curtos com terminaçóes em uma ou mais, raramente nas duas, pontas; seçóes basais triangulares ou hexagonais; e finalmente em agregados colunares e aciculares (Mange \& Maurer 1992). No presente estudo, os grãos que apresentavam pelo menos três faces bem desenvolvidas foram considerados como 
Felipe Lamus Ochoa et al.

Quadro 1. Quadro comparativo sobre a estratigrafia da Bacia Paraíba

\begin{tabular}{|c|c|c|c|c|c|c|}
\hline \multicolumn{3}{|c|}{ Beurlen 1967} & \multicolumn{2}{|c|}{ Barbosa et al. 2007} & \multicolumn{2}{|c|}{ Projeto Paraíba 2010} \\
\hline 号 & Formação & Idade & Formação & Idade & Formação & Idade \\
\hline \multirow{5}{*}{ 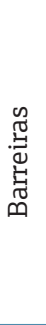 } & $\begin{array}{l}\text { *Aluviões } \\
\text { etc. }\end{array}$ & $\begin{array}{c}\text { Pleistoceno - } \\
\text { Holoceno }\end{array}$ & \multirow{5}{*}{ Barreiras } & \multirow{5}{*}{ Plioceno - Pleistoceno (?) } & *Aluviões & \multirow{3}{*}{ Holoceno } \\
\hline & Potengí (?) & \multirow[b]{2}{*}{ Pleistoceno (?) } & & & & \\
\hline & Macaiba & & & & $\begin{array}{l}\text { *Pós- } \\
\text { Barreiras II }\end{array}$ & \\
\hline & $\begin{array}{l}\text { Riacho } \\
\text { Morno }\end{array}$ & $\begin{array}{c}\text { Plioceno - } \\
\text { Pleistoceno (?) }\end{array}$ & & & $\begin{array}{c}\text { *Pós- } \\
\text { Barreiras I }\end{array}$ & Neopleistoceno \\
\hline & Guararapes & Mioceno(?) & & & Barreiras & Mioceno \\
\hline \multirow{4}{*}{ 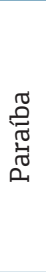 } & $\begin{array}{l}\text { Maria } \\
\text { Farinha }\end{array}$ & $\begin{array}{c}\text { Paleoceno - } \\
\text { Eoceno(?) }\end{array}$ & $\begin{array}{l}\text { Maria } \\
\text { Farinha }\end{array}$ & Paleoceno - Eoceno(?) & $\begin{array}{l}\text { Maria } \\
\text { Farinha }\end{array}$ & Paleoceno - Eoceno(?) \\
\hline & \multirow[b]{2}{*}{ Gramame } & \multirow[b]{2}{*}{ Maastrichtiano } & Gramame & Maastrichtiano & Gramame & Maastrichtiano \\
\hline & & & Itamaracá & $\begin{array}{l}\text { Neocampaniano - } \\
\text { Eomaastrichtiano }\end{array}$ & Itamaracá & $\begin{array}{l}\text { Neocampaniano - } \\
\text { Eomaastrichtiano }\end{array}$ \\
\hline & Beberibe & $\begin{array}{l}\text { Santoniano- } \\
\text { Campaniano }\end{array}$ & Beberibe & $\begin{array}{l}\text { Coniaciano (?) - } \\
\text { Santoniano }\end{array}$ & Beberibe & Coniaciano (?) - Santoniano \\
\hline
\end{tabular}

*Unidades informais.

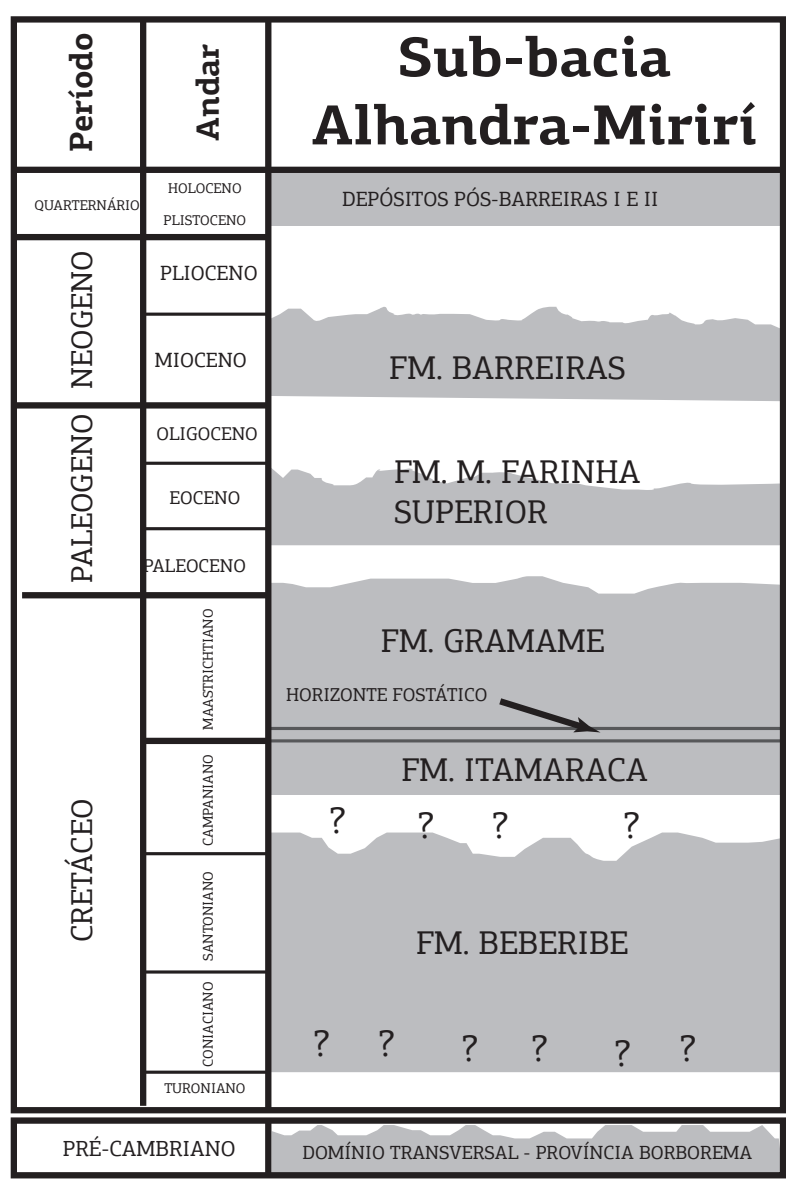

Figura 2. Coluna estratigráfica da Bacia Paraíba, modificada de Barbosa et al. (2007). subeuedrais. Assim, as categorias determinadas foram as seguintes:

- Zircão: euedrais (Z1); subeuedrais angulosos (Z2); subeuedrais arredondados (Z3); angulosos e muito angulosos (Z4); subangulosos (Z5); subarredondados (Z6); arredondados e bem arredondados (Z7). Para facilitar os cálculos e a visualização dos resultados, as sete categorias acima relacionadas são agrupadas em três tipos de zircão: $\mathrm{Za}=(Z 1+Z 2+Z 4), Z b=(Z 3+Z 5)$ e $Z c=$ (Z6+Z7).

- Turmalina: euedrais e subeuedrais (T1); muito angulosas e angulosas (T2); subangulosas (T3); subarredondadas (T4); arredondadas e bem arredondadas (T5). Para simplificação, as cinco categorias de turmalina acima citadas são agrupadas em: $\mathrm{Ta}=(\mathrm{T} 1+\mathrm{T} 2), \mathrm{Tb}=(\mathrm{T} 3)$ $\mathrm{e} \mathrm{Tc}=(\mathrm{T} 4+\mathrm{T} 5)$.

\section{Análise estatística}

Os dados de minerais pesados categorizados por unidades estratigráficas foram resumidos por estatísticas descritivas e gráficos (boxplots). Gráficos de dispersão foram utilizados para avaliar a dependência entre pares de variáveis.

Análises de componentes principais e de agrupamentos realizadas com frequências de ocorrência de minerais pesados, morfologia de grãos de turmalina, diâmetro médio e desvio padrão da granulação foram utilizadas para avaliar a similaridade mineralógica e textural das amostras coletadas na Formação Barreiras e Sedimentos Pós-Barreiras. 


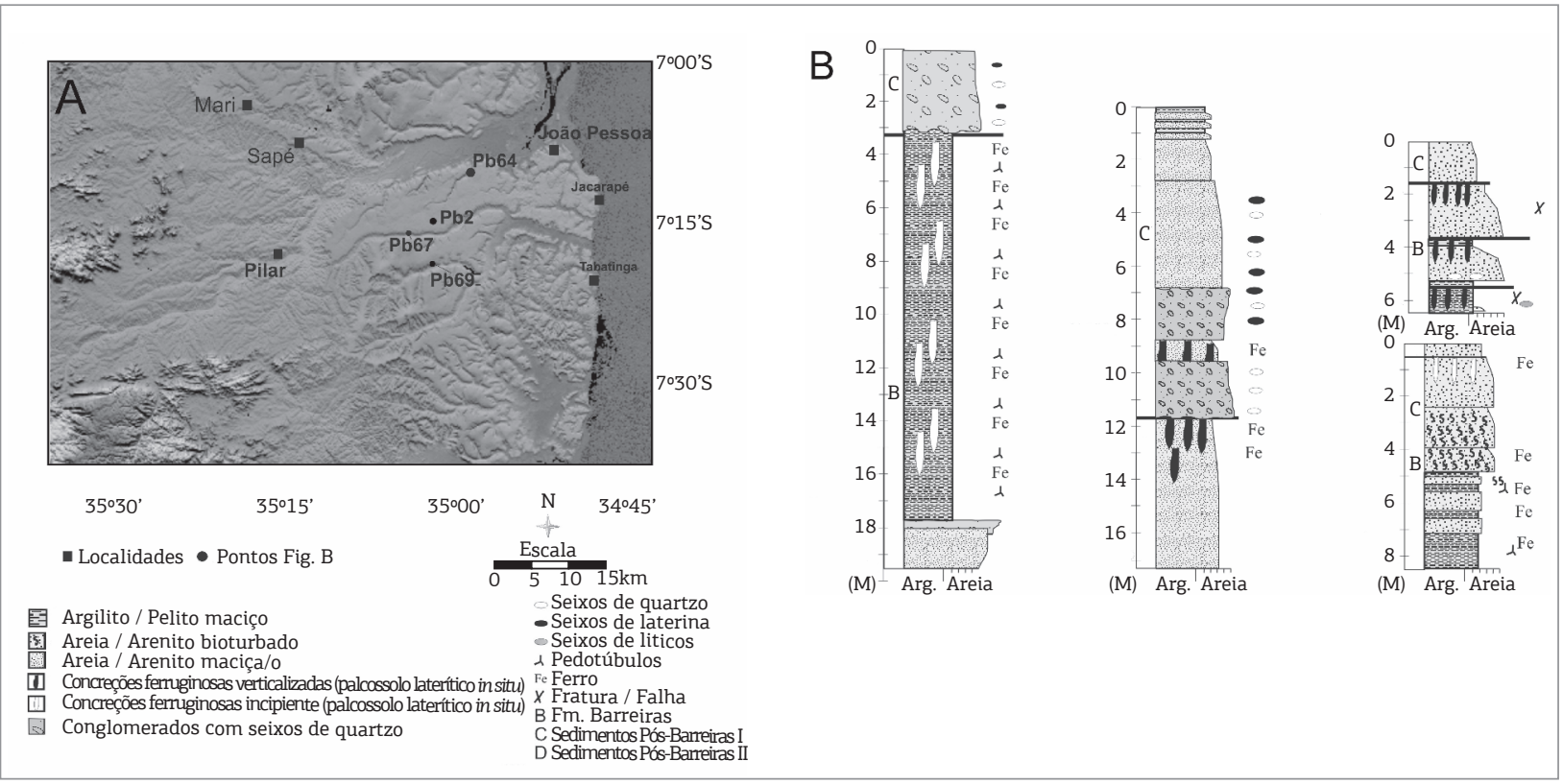

Figura 3. (A) Mapa de localização de pontos de afloramentos representativos da Formação Barreiras e dos Sedimentos Pós-Barreiras I e Pós-Barreiras II. (B) Seções colunares dos pontos citados anteriormente.

A medida de similaridade utilizada na análise de agrupamento foi a distância euclidiana ao quadrado e o método Ward para o agrupamento. O método de Ward aglomera as observaçóes em grupos homogêneos com variâncias mínimas e diferentes entre si. As variáveis composicionais, representadas por porcentagens ou frequências relativas (exemplos: frequências de minerais ou classes morfológicas de turmalinas), foram transformadas por função logarítmica clr (Centered Log-Ratio) para evitar o efeito de correlaçóes espúrias inerentes aos dados composicionais sobre as análises estatísticas multivaridas (Aitchison 1982). Para um conjunto de dados composicionais representados por $i$ componentes $\left(\mathrm{x}_{1}\right.$, $\left.\mathrm{x}_{2}, \ldots \mathrm{x}_{\mathrm{i}}\right)$, a transformação clr é representada pela equação a seguir:

$\operatorname{clr}\left[x_{1}, x_{2}, \mathrm{~K}, x_{i}\right]=\left[\ln \frac{x_{1}}{\left(x_{1} \cdot x_{2} \cdot \mathrm{K} \cdot x_{i}\right)^{1 / i}}\right.$, $\left.\ln \frac{x_{2}}{\left(x_{1} \cdot x_{2} \cdot \mathrm{K} \cdot x_{i}\right)^{1 / i}}, \mathrm{~K}, \ln \frac{x_{2}}{\left(x_{1} \cdot x_{2} \cdot \mathrm{K} \cdot x_{i}\right)^{1 / i}}\right]$

Minerais presentes nas amostras estudadas, porém não computados durante a quantificação da assembleia, foram representados por frequência relativa mínima $(0,1)$ para realização da transformação logarítmica. As análises multivariadas foram realizadas com variáveis normalizadas. A associação entre as unidades estratigráficas estudadas e os grupos de observaçóes baseados em variáveis mineralógicas e composicionais foi avaliada por teste qui-quadrado, segundo método descrito por Magalhães e Lima (2002). Todas as análises estatísticas foram realizadas por meio do software Minitab Release 15.0.

Para a realização das análises de componentes principais e de agrupamento, foram processados os dados granulométricos, mineralógicos e morfológicos de turmalina de 115 amostras.

\section{RESULTADOS}

\section{Estratigrafia}

O mapa geológico apresentado na Fig. 4 mostra domínio de unidades cenozoicas na área de estudo, a despeito da Formação Beberibe ter sido registrada em mapas geológicos e publicaçôes anteriores (por exemplo, Beurlen 1967, Brasil 1982, 2002, Brito Neves et al. 2009). Durante a realização deste trabalho, não foram encontradas evidências de exposição da Formação Beberibe, reconhecida a partir de $102 \mathrm{~m}$ de profundidade em poço da localidade de João Pessoa (Lamus Ochoa 2010).

A unidade siliciclástica mais antiga que aflora na região de estudo é a Formação Barreiras, exposta dominantemente na porção sudeste da área, onde ocorrem suas maiores espessuras registradas com cerca de $75 \mathrm{~m}$. Os depósitos, de coloração branca, rósea avermelhada e amarelada, consistem em arenitos finos a grossos, moderada a pobremente selecionados, maciços ou estratificados, que ocorrem 
intercalados a argilitos maciços ou com laminação plano - paralela. Subordinadamente, ocorrem conglomerados finos a grossos, constituídos de seixos de quartzo dispersos em matriz arenosa média a grossa e mal selecionada. Não é rara a presença de bioturbaçóes atribuídas a Ophiomorpha, Planolites e Diplocraterion. Destaca-se a existência de uma crosta laterítica desenvolvida no topo da Formação Barreiras, cujas dataçóes de U-Th/He em goetita suportam desenvolvimento de paleossolos entre o final do Mioceno e o Pleistoceno (Rossetti et al. 2012). Dada a ausência de fósseis-guias, esses resultados cronológicos sugerem que essa unidade deve ser mais velha que aproximadamente $17 \mathrm{mi}$ lhôes de anos.

Sobrepostos aos arenitos da Formação Barreiras encontram-se vários depósitos siliciclásticos informalmente chamados de Sedimentos Pós-Barreiras, cujas dataçóes por luminescência opticamente estimulada de quartzo (LOE-SAR) permitiram separá-los em dois conjuntos: Pós-Barreiras I, com deposição entre $178.300( \pm 26.800)$ e $15.100( \pm 1.800)$ anos, e Pós-Barreiras II, com idades entre $11.300( \pm 1.700)$ e 1800 ( \pm 200$)$ anos (Rossetti et al. 2011b). Os Sedimentos PósBarreiras I (Pleistoceno Tardio) ocorrem em grande parte da área estudada, como cobertura da Formação Barreiras ou diretamente acima do embasamento cristalino da Bacia Paraíba. Suas espessuras tornam-se mais significativas nas proximidades da costa, onde podem atingir até $20 \mathrm{~m}$ de espessura. Tratase de um complexo de depósitos de areias e arenitos conglomeráticos, em geral maciços, e raramente com estratificaçóes cruzadas incipientes, mal selecionados, de coloraçáo que varia de avermelhada a rósea, a amarelo-clara e amarronzada. Apesar de, em geral, apresentarem baixo grau de consolidação, ocorrem depósitos endurecidos, de cores amarelo-dourada, amarelo-esbranquiçada e branca, com abundantes estruturas de deformaçóes sin-sedimentares, que foram atribuídos a sismitos (Rossetti et al. 2011a). Os Sedimentos Pós-Barreiras I podem conter fragmentos de laterita ferruginosa de diferentes tamanhos e em volumes variáveis, o que não é observado na Formação Barreiras, a qual apresenta a crosta laterítica in situ. Os Sedimentos Pós-Barreiras II incluem areias holocênicas friáveis, brancas, e secundariamente cinzas, amarronzadas e amareladas, de granulometria média a grossa, por vezes finas, moderada a pobremente selecionada. Essas areias ocorrem em discordância sobre os demais estratos da área de estudo e também diretamente sobre rochas do embasamento cristalino. Os depósitos arenosos, com espessuras inferiores a $7 \mathrm{~m}$, afloram predominantemente na parte central e setentrional da área de estudo e foram encontrados em cotas topográficas distintas, desde o litoral até as topografias mais elevadas da região ( $\pm 400 \mathrm{~m})$. Em geral, as areias dessa unidade são maciças, porém em várias localidades observam-se estruturas de bandas de infiltração.

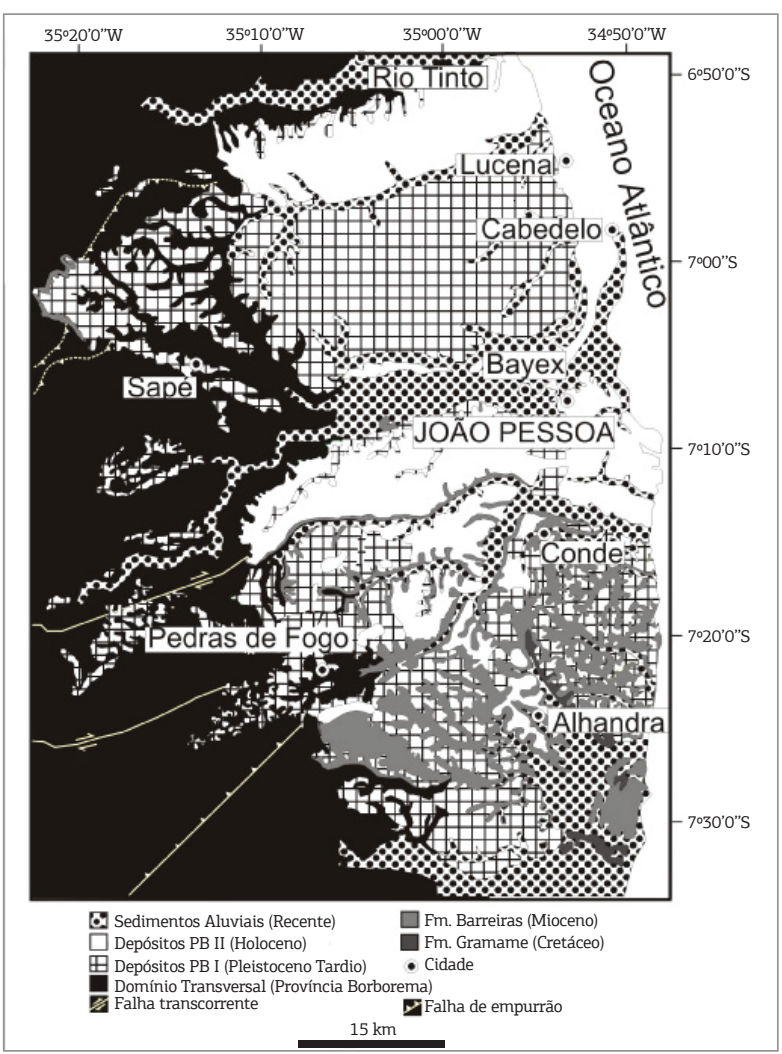

Figura 4. Mapa geológico da área estudada, segundo Rossetti et al. (2011a, 2011b, 2012).

\section{Análise granulométrica}

Os resultados da análise granulométrica demonstram tendência de sedimentos mais grossos e com maior grau de seleção nos Sedimentos Pós-Barreiras II (areias médias) do que na Formação Barreiras e nos Sedimentos Pós-Barreiras I (areias finas) (Tab. 1 e Fig. 5). No gráfico de dispersão do diâmetro médio versus desvio padrão (Fig. 6), são diferenciados dois grupos de sedimentos, um mais arenoso com melhor seleção granulométrica (GR 2) e outro com maior proporção de fraçóes pelíticas e pior seleção granulométrica (GR 1). O agrupamento GR 1 é mais heterogêneo e reúne amostras de todas as unidades estratigráficas, principalmente da Formação Barreiras e dos Sedimentos Pós-Barreiras I. O grupo GR 2 também inclui todas as unidades cenozoicas, porém é mais homogêneo e contém principalmente amostras dos Sedimentos Pós-Barreiras I e II.

\section{Análise de minerais pesados e morfologia de grãos de zircão e turmalina}

Descrição dos minerais pesados

A assembleia de minerais pesados translúcidos não micáceos apresenta dominantemente zircão, turmalina, cianita e rutilo. Minerais subordinados incluem estaurolita, andaluzita, topázio e anfibólios cálcicos. Além destes, 
ocorrem sillimanita, epídoto, monazita, granada e espinélio como minerais traços (Fig. 7).

\section{Estatistica descritiva}

A assembleia de minerais pesados (Tab. 2) apresenta porcentagens inferiores a $40 \%$ de minerais translúcidos não micáceos, nos quais os minerais principais com ocorrência em todas as amostras estudadas (Fig. 8) são zircão (valores médios de 55\% na Formação Barreiras e nos Sedimentos Pós-Barreiras I e 68\% nos Sedimentos Pós-Barreiras II), turmalina (valores médios de 22\% na Formação Barreiras, 25\% nos Sedimentos Pós-Barreiras I e 14\% nos Sedimentos PósBarreiras II), cianita (valores médios de $10 \%$ na Formação Barreiras, 8\% nos Sedimentos Pós-Barreiras I e 7\% nos Sedimentos Pós-Barreiras II) e rutilo (valores médios de 4\% na Formação Barreiras e 5\% nos Sedimentos Pós-Barreiras I e II). Como minerais subordinados com proporçóes inferiores a 5\% em todas as unidades (Fig. 9) ocorrem estaurolita (médias entre 3 e 4\%), andaluzita (médias entre 2 e 1\%) e topázio (média 1\%), anfibólios cálcicos (médias inferiores ou iguais a $1 \%$ ). Como minerais traços ocorrem sillimanita, granada, monazita, epídoto e espinélio. Localmente, os anfibólios cálcicos e a sillimanita podem ocorrer como minerais principais e alcançam 17 e $21 \%$, respectivamente. $\mathrm{O}$ índice ZTR (Fig. 10) apresenta um incremento na direção do topo, com valores de 81 na Formação Barreiras, 85 nos Sedimentos Pós-Barreiras I e 87 nos Sedimentos PósBarreiras II. As médias do índice RZ (Fig. 10) apresentam pequena variação entre as unidades estudadas (entre 9 e 11).

As análises morfológicas de zircão (Tab. 2, Fig. 11A) indicam incremento de categorias com maior arredondamento (Zc) nos Sedimentos Pós-Barreiras II onde essa classe de grãos alcança $63 \%$ diante dos $50 \%$ nos Sedimentos Pós-Barreiras I e 52\% na Formação Barreiras. A turmalina é ainda mais sensível como elemento diferenciador das unidades estudadas. É marcante a tendência de ocorrência das categorias arredondadas (Tc) na direção das unidades mais jovens, com a Formação Barreiras apresentando 23\% de grãos arredondados, os Sedimentos Pós-Barreiras I, 40\% e os Sedimentos Pós-Barreiras II, 51\% (Tab. 2, Fig. 11B)

\section{Estatistica multivariada}

A análise de componentes principais realizada com a proporção de tipos de minerais pesados indica relativa semelhança entre a Formação Barreiras e os Sedimentos PósBarreiras. Os dois primeiros componentes principais explicam $43 \%$ da variabilidade mineralógica dos dados e apresentam baixa capacidade de discriminação dos sedimentos das unidades cenozoicas em estudo (Fig. 12A). A Formação Barreiras e os Sedimentos Pós-Barreiras I apresentam a maior variabilidade mineralógica, enquanto

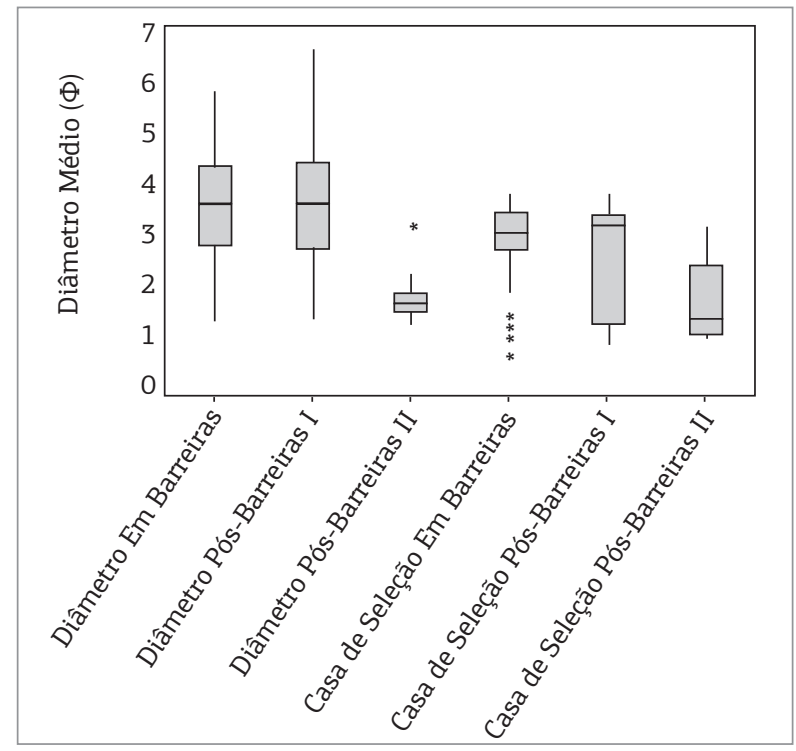

Figura 5. Gráficos em caixa dos parâmetros granulométricos encontrados nos depósitos cenozoicos da Bacia Paraíba.

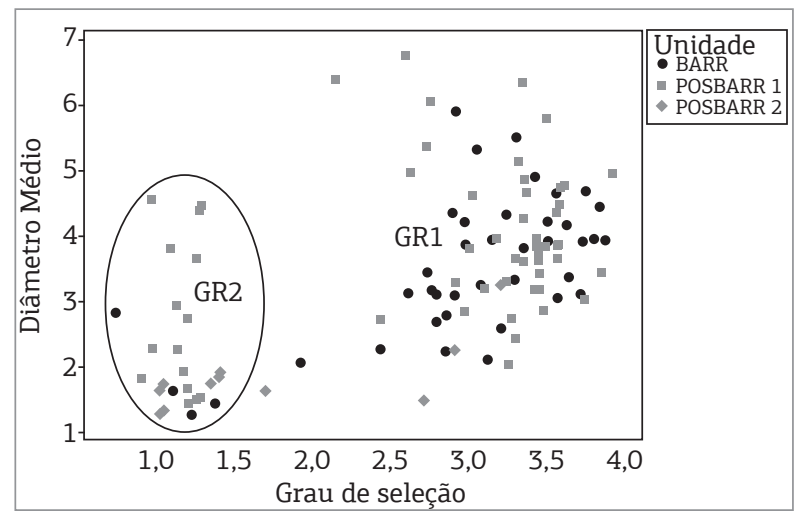

Figura 6. Gráficos de dispersão do diâmetro médio versus grau de seleção dos depósitos cenozoicos da Bacia Paraíba.

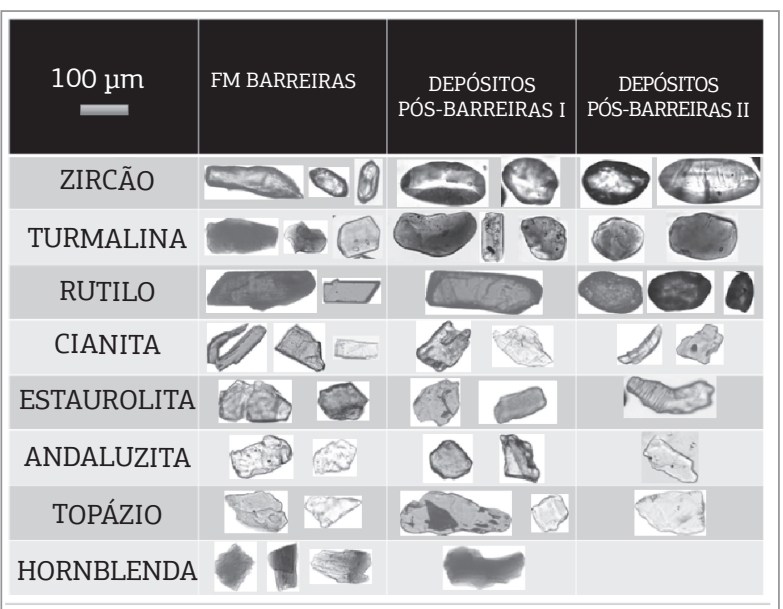

Figura 7. Micrografias dos minerais principais e subordinados dos depósitos cenozoicos da Bacia Paraíba. 
Tabela 1. Parâmetros granulométricos dos arenitos da Formação Barreiras, dos Sedimentos Pós-Barreiras I e PósBarreiras II

\begin{tabular}{|c|c|c|c|c|c|c|c|}
\hline \multirow[t]{2}{*}{ Unidade } & \multirow[t]{2}{*}{$\mathbf{N}$} & \multirow[t]{2}{*}{ Estatística } & $\begin{array}{l}\text { Diâmetro } \\
\text { médio }\end{array}$ & $\begin{array}{l}\text { Diâmetro } \\
\text { médio }\end{array}$ & \multirow{2}{*}{$\begin{array}{l}\text { Classe } \\
\text { textural }\end{array}$} & \multirow{2}{*}{$\begin{array}{l}\text { Desvio } \\
\text { padrão }\end{array}$} & \multirow{2}{*}{$\begin{array}{l}\text { Grau de } \\
\text { seleção }\end{array}$} \\
\hline & & & $\Phi$ & $\mathrm{Mm}$ & & & \\
\hline \multirow{4}{*}{ Pós-barreiras II } & \multirow{4}{*}{12} & Máximo & 3,26 & 0,41 & $\begin{array}{l}\text { areia muito } \\
\text { fina }\end{array}$ & 3,19 & $\begin{array}{l}\text { pobremente } \\
\text { seleccionado }\end{array}$ \\
\hline & & Mínimo & 1,30 & 0,10 & areia média & 1,03 & $\begin{array}{l}\text { pobremente } \\
\text { seleccionado }\end{array}$ \\
\hline & & Desvio padrão & 0,52 & 0,08 & - & 0,79 & - \\
\hline & & Média & 1,81 & 0,30 & areia média & 1,67 & $\begin{array}{l}\text { pobremente } \\
\text { seleccionado }\end{array}$ \\
\hline \multirow{4}{*}{ Pós-barreiras I } & \multirow{4}{*}{65} & Máximo & 6,77 & 0,38 & $\begin{array}{l}\text { areia muito } \\
\text { fina }\end{array}$ & 3,88 & $\begin{array}{l}\text { pobremente } \\
\text { seleccionado }\end{array}$ \\
\hline & & Mínimo & 1,39 & 0,01 & areia média & 0,92 & $\begin{array}{l}\text { pobremente } \\
\text { seleccionado }\end{array}$ \\
\hline & & Desvio padrão & 1,31 & 0,11 & - & 0,97 & - \\
\hline & & Média & 3,60 & 0,12 & $\begin{array}{l}\text { areia muito } \\
\text { fina }\end{array}$ & 2,71 & $\begin{array}{l}\text { pobremente } \\
\text { seleccionado }\end{array}$ \\
\hline \multirow{4}{*}{ Barreiras } & \multirow{4}{*}{42} & Máximo & 5,90 & 0,42 & $\begin{array}{l}\text { areia muito } \\
\text { fina }\end{array}$ & 3,83 & $\begin{array}{l}\text { pobremente } \\
\text { seleccionado }\end{array}$ \\
\hline & & Mínimo & 1,25 & 0,02 & areia média & 0,75 & $\begin{array}{l}\text { pobremente } \\
\text { seleccionado }\end{array}$ \\
\hline & & Desvio padrão & 1,18 & 0,09 & - & 0,74 & - \\
\hline & & Média & 3,63 & 0,11 & $\begin{array}{l}\text { areia muito } \\
\text { fina }\end{array}$ & 2,97 & $\begin{array}{l}\text { pobremente } \\
\text { seleccionado }\end{array}$ \\
\hline
\end{tabular}

amostras dos Sedimentos Pós-Barreira II, exceto por uma amostra, apresentam valores positivos da primeira componente. Desse modo, os Sedimentos Pós-Barreiras II assemelham-se apenas em parte à Formação Barreiras e aos Sedimentos Pós-Barreiras I, sendo enriquecida em minerais contribuintes para os valores positivos da primeira componente principal (granada, cianita, anfibólios cálcicos, rutilo e zircão) (Fig. 12B).

A análise de agrupamento conduzida com variáveis mineralógicas (proporçôes de tipos de minerais pesados) e com classes texturais de grãos de turmalina revelou estrutura caracterizada por dois grupos. Apesar de os dendrogramas de mineralogia (Fig. 13) e morfologia de turmalina (Fig. 14) apresentarem dois grupos com maiores diferenças entre si, a análise detalhada de cada uma dessas configuraçóes indica que elas têm estruturas diferentes. Os dois grupos definidos pelas variáveis granulométricas (GR1 e GR2) e pelas classes texturais de turmalina (MA1 e MA2) são mais homogêneos e distintos entre si, se comparados aos grupos definidos pelos tipos de minerais pesados. A associação entre as unidades estratigráficas (Formação Barreiras e Sedimentos Pós-Barreiras indiferenciado) e os grupos mineralógicos e texturais (granulometria e classes de turmalina) foi avaliada por teste qui-quadrado. Valores p menores que 0,05 indicam associação significativa. Os resultados do teste qui-quadrado estão resumidos na Tab. 3. A Tab. 4 apresenta as características dos grupos mineralógicos e de arredondamento de grãos de turmalina. Assim, foi notada associação significativa entre a Formação Barreiras e os Sedimentos Pós-Barreiras e os grupos granulométricos-texturais GR1-MA1 e GR2-MA2, respectivamente (Tab. 3). A ausência de associação entre a assembleia de minerais pesados e a Formação Barreiras e Sedimentos Pós-Barreiras indica composição similar. A Formação 
Tabela 2. Estatística descritiva dos minerais pesados translúcidos, índices mineralógicos e morfologia de grãos de zircão e turmalina dos depósitos cenozoicos da Bacia Paraíba

\begin{tabular}{|c|c|c|c|c|c|c|c|c|c|c|c|c|c|c|c|c|c|c|c|c|c|c|c|}
\hline UNIDADE & ESTATÍSTICA & $\mathbf{N}$ & Cia & Est & And & Top & Anf & Gra & 0 & $\mathbf{T}$ & $\mathbf{z}$ & $\mathbf{R}$ & ZIR & $\mathbf{R Z i}$ & $\operatorname{Tr}$ & $\mathbf{N}$ & $\mathrm{Za}$ & $\mathbf{Z b}$ & Zc & $\mathbf{N}$ & Ta & Tb & Tc \\
\hline \multirow{4}{*}{ 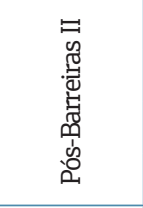 } & Máximo & \multirow{4}{*}{12} & 21 & 12 & 2 & 3 & 3 & 1 & 1 & 29 & 86 & 9 & 95 & 23 & 51 & \multirow{4}{*}{6} & 12 & 38 & 70 & \multirow{4}{*}{12} & 37 & 46 & 73 \\
\hline & Mínimo & & 1 & 0 & 0 & 0 & 0 & 0 & 0 & 3 & 42 & 2 & 75 & 3 & 19 & & 3 & 27 & 50 & & 11 & 11 & 33 \\
\hline & Desvio padrão & & 6 & 4 & 1 & 1 & 1 & 0 & 0 & 8 & 12 & 2 & 6 & 5 & 11 & & 4 & 5 & 7 & & 7 & 10 & 12 \\
\hline & Média & & 7 & 4 & 1 & 1 & 0 & 0 & 0 & 14 & 68 & 5 & 87 & 10 & 33 & & 5 & 32 & 63 & & 22 & 27 & 51 \\
\hline \multirow{4}{*}{ 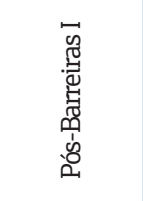 } & Máximo & \multirow{4}{*}{65} & 27 & 17 & 9 & 9 & 3 & 2 & 10 & 63 & 84 & 13 & 97 & 29 & 78 & \multirow{4}{*}{35} & 22 & 73 & 71 & \multirow{4}{*}{62} & 56 & 55 & 72 \\
\hline & Mínimo & & 0 & 0 & 0 & 0 & 0 & 0 & 0 & 2 & 20 & 0 & 63 & 1 & 3 & & 1 & 28 & 14 & & 8 & 16 & 4 \\
\hline & Desvio padrão & & 6 & 3 & 2 & 2 & 1 & 0 & 2 & 13 & 17 & 2 & 8 & 5 & 14 & & 6 & 9 & 14 & & 11 & 10 & 14 \\
\hline & Média & & 8 & 4 & 2 & 1 & 0 & 0 & 1 & 25 & 55 & 5 & 85 & 9 & 37 & & 8 & 42 & 50 & & 27 & 33 & 40 \\
\hline \multirow{4}{*}{ 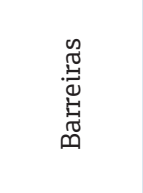 } & Máximo & \multirow{4}{*}{42} & 35 & 10 & 13 & 7 & 17 & 1 & 21 & 56 & 83 & 13 & 97 & 26 & 76 & \multirow{4}{*}{35} & 18 & 50 & 65 & \multirow{4}{*}{42} & 69 & 74 & 70 \\
\hline & Mínimo & & 1 & 0 & 0 & 0 & 0 & 0 & 0 & 4 & 16 & 1 & 53 & 1 & 4 & & 3 & 31 & 38 & & 6 & 19 & 2 \\
\hline & Desvio padrão & & 8 & 3 & 3 & 2 & 3 & 0 & 4 & 13 & 19 & 2 & 11 & 6 & 12 & & 4 & 5 & 7 & & 13 & 11 & 15 \\
\hline & Média & & 10 & 3 & 2 & 1 & 1 & 0 & 0 & 22 & 55 & 4 & 81 & 11 & 35 & & 9 & 39 & 52 & & 36 & 41 & 23 \\
\hline
\end{tabular}

Cia: cianita; Est: estaurolita; And: andaluzita; Top: topázio; Anf: anfibólio cálcico; Gra: Granada Out: outros minerais pesados transparentes (espinélio, dumortierita, monazita); Tur: turmalina; Zir: zircão; Rut: rutilo, ZTR: $\sum$ \% zircão, turmalina, rutilo; RZi: índice rutilo-zircão; Tr: \% translúcidos em relação aos opacos; Za: euédrico + subeuédrico anguloso + anédrico anguloso; Zb:subeuédrico arredondado + subanguloso; Zc: subarredondado + arredondado Ta: euédrico e subeuédrico + anédrico anguloso e muito anguloso + anédrico anguloso; Tb: anédrico subanguloso; Tc: subarredondado + arredondado e muito arredondado; $\mathrm{N}$ : número de amostras analisadas.

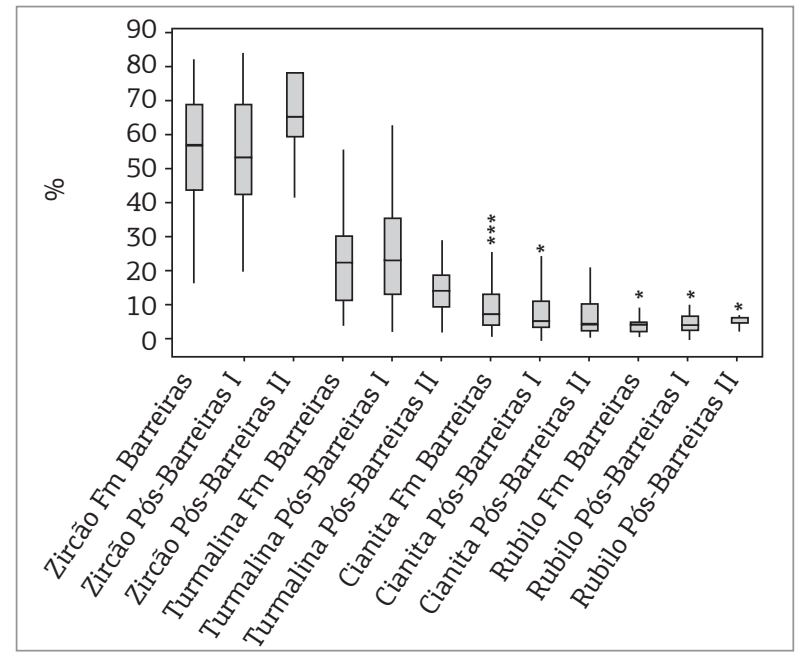

Figura 8. Gráficos de caixa das frequências percentuais dos minerais pesados principais nos depósitos cenozoicos da Bacia Paraíba.

Barreiras associa-se aos grupos GR1 (mais fino e pior selecionado) e MA1 (turmalinas mais angulosas), enquanto os Sedimentos Pós-Barreiras estão relacionados aos grupos GR2 (mais grosso e melhor selecionado) e MA2 (turmalinas mais arredondadas) (Tab. 4). A associação mais forte encontrada foi entre as morfologias de turmalina e as unidades estratigráficas. Nesse caso, o arredondamento dos grãos de turmalina seria

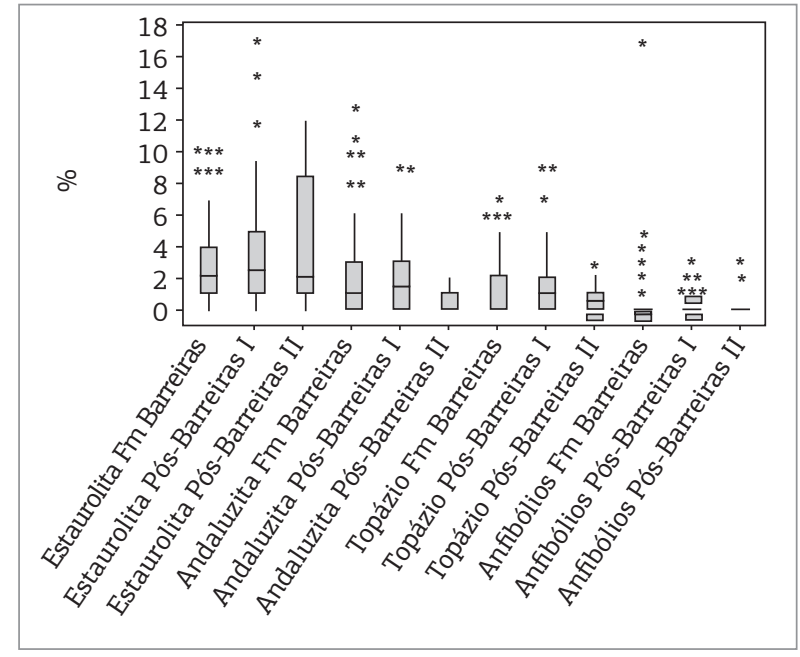

Figura 9. Gráficos de caixa das frequências percentuais dos minerais pesados subordinados nos depósitos cenozoicos da Bacia Paraíba.

a melhor variável de discriminação entre a Formação Barreiras e os Sedimentos Pós-Barreiras.

\section{DISCUSSÃO}

Os resultados de minerais pesados indicam que as variaçôes composicionais da Formação Barreiras e dos 


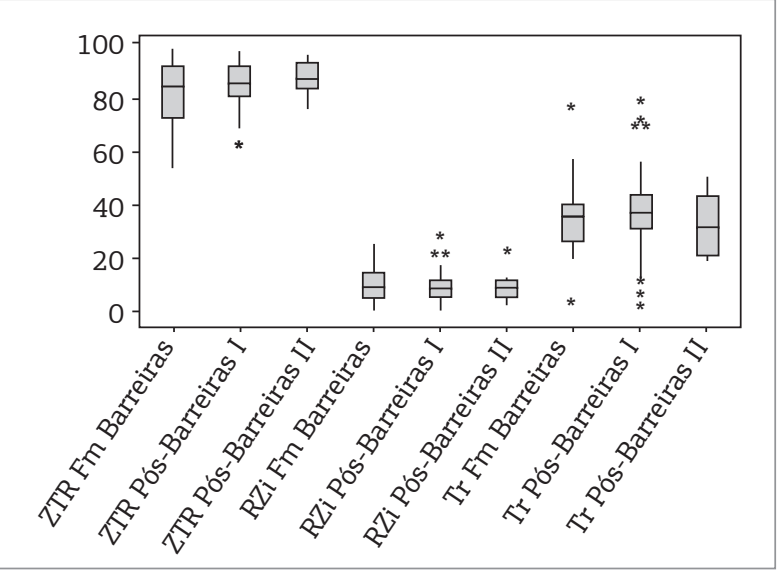

Figura 10. Gráficos de caixa das frequências percentuais da relação translúcidos e dos índices mineralógicos (ZTR e RZi) nos depósitos cenozoicos da Bacia Paraíba.
Sedimentos Pós-Barreiras são maiores que as variações interunidades (Tab. 2 e Figs. 8 a 10). Esse fato sugere mesma fonte sedimentar para essas unidades geológicas. Portanto, mineralogia não pode ser utilizada como fator de discriminação das unidades estratigráficas da sucessão cenozoica da Bacia Paraíba.

Por outro lado, as características granulométricas (Fig. 6) diferenciam dois grupos de sedimento. A Formação Barreiras compreende amostras mais pelíticas relativamente aos depósitos mais arenosos dos Sedimentos Pós-Barreiras I e II. Essas tendências de agrupamentos foram testadas em relação às suas localizações geográficas, sem que nenhuma diferenciação pudesse ser identificada. Isso demonstra que esses agrupamentos caracterizam toda a extensão de exposição dos depósitos cenozoicos.
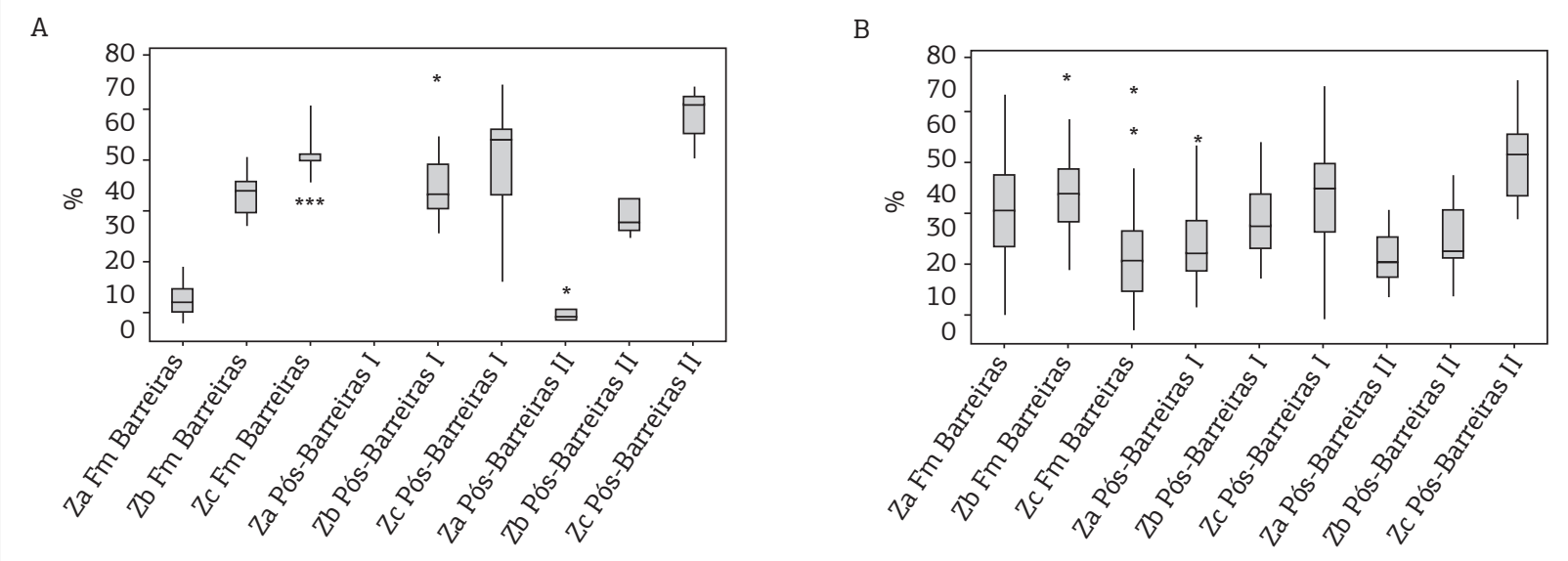

Figura 11. Gráficos de caixa das frequências percentuais das categorias da morfologia de grãos de zircão (A) e turmalina (B). Za: euédrico + subeuédrico anguloso + anédrico anguloso; $\mathrm{Zb}$ : subeuédrico arredondado + anédrico subanguloso; Zc: subarredondado + arredondado Ta: euédrico e subeuédrico + anédrico anguloso e muito anguloso + anédrico anguloso; Tb: anédrico subanguloso; Tc: subarredondado + arredondado e muito arredondado.
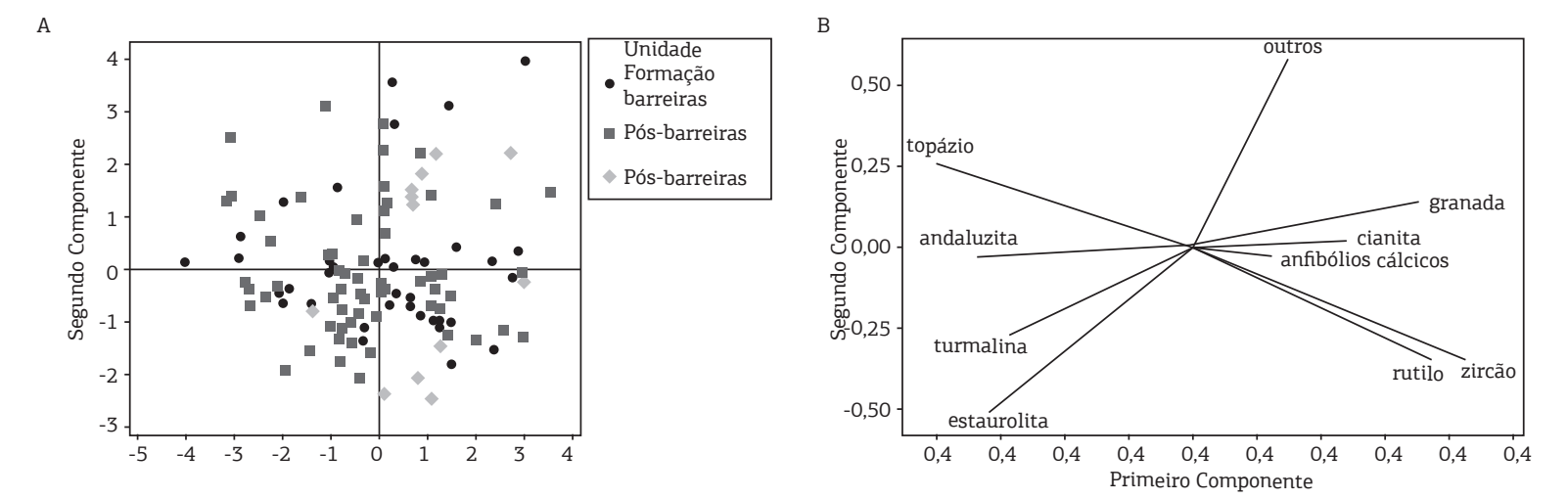

Figura 12. (A) Gráfico de dispersão do primeiro e do segundo componentes da assembleia de minerais pesados translúcidos dos depósitos cenozoicos da Bacia Paraíba; (B) Peso das variáveis mineralógicas para o primeiro e o segundo componentes mineralógicos. 


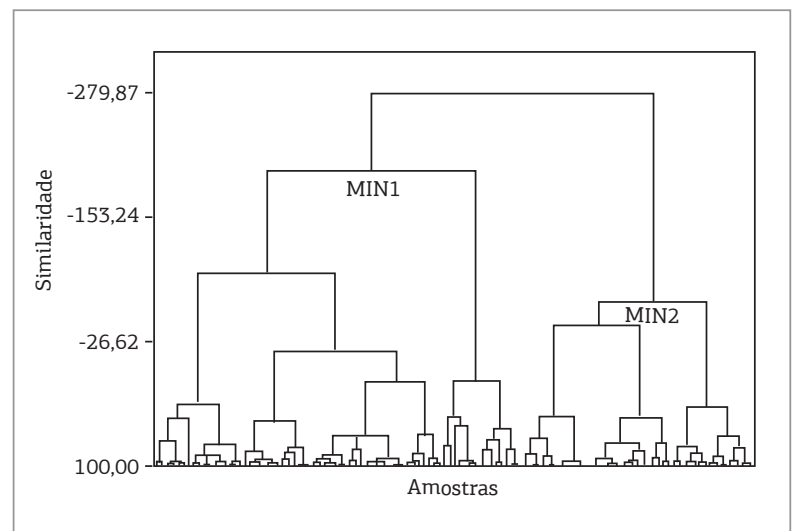

Figura 13. Dendograma da mineralogia dos depósitos cenozoicos da Bacia da Paraíba.

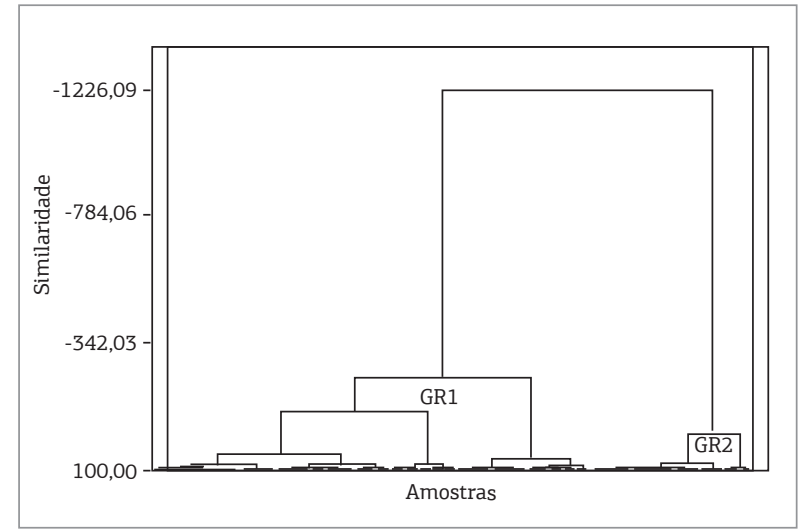

Figura 14. Dendograma da forma e arredondamento dos grãos de turmalina dos depósitos cenozoicos da Bacia da Paraíba.

Tabela 3. Correspondência de teste qui-quadrado para avaliar a dependência entre os grupos encontrados (Figs. 13-14)

\begin{tabular}{|c|c|c|c|c|}
\hline & & & \multicolumn{2}{|c|}{ Estratigrafia } \\
\hline & & & FM barreiras & Pós-barreiras \\
\hline \multirow{4}{*}{ Mineralogia } & \multirow{2}{*}{ Grupo MIN 1} & Freq. observada & 23 & 47 \\
\hline & & Freq. esperada & 24,96 & 45,04 \\
\hline & \multirow{2}{*}{ Grupo MIN 2} & Freq. observada & 18 & 27 \\
\hline & & Freq. esperada & 16,04 & 28,96 \\
\hline \multicolumn{5}{|c|}{ Teste qui-quadrado } \\
\hline \multirow[t]{3}{*}{ Qui-quadrado=0,609 } & & Graus de liberdade $=1$ & & $p=0,435$ \\
\hline & & & \multicolumn{2}{|c|}{ ESTRATIGRAFIA } \\
\hline & & & FM BARREIRAS & PÓS-BARREIRAS \\
\hline \multirow{4}{*}{ Granulometria } & \multirow{2}{*}{ Grupo GR 1} & Freq. observada & 36 & 48 \\
\hline & & Freq. esperada & 29,95 & 54,05 \\
\hline & \multirow{2}{*}{ Grupo GR 2} & Freq. observada & 5 & 26 \\
\hline & & Freq. esperada & 11,05 & 19,95 \\
\hline \multicolumn{5}{|c|}{ Teste qui-quadrado } \\
\hline \multirow[t]{3}{*}{ Qui-quadrado=7,051 } & & Graus de liberdade $=1$ & & $p=0,008$ \\
\hline & & & \multicolumn{2}{|c|}{ ESTRATIGRAFIA } \\
\hline & & & FM BARREIRAS & PÓS-BARREIRAS \\
\hline \multirow{4}{*}{$\begin{array}{l}\text { Morfologia e } \\
\text { arredondamento }\end{array}$} & \multirow{2}{*}{ Grupo MA 1} & Freq. observada & 24 & 8 \\
\hline & & Freq. esperada & 11,41 & 20,59 \\
\hline & \multirow{2}{*}{ Grupo MA 2} & Freq. observada & 17 & 66 \\
\hline & & Freq. esperada & 29,59 & 53,41 \\
\hline \multicolumn{5}{|c|}{ Teste qui-quadrado } \\
\hline Qui-quadrado= &, 922 & Graus d & $e=1$ & $p=0,000$ \\
\hline
\end{tabular}


Tabela 4. Estatística descritiva das variáveis associadas dos grupos encontrados (Figs. 13-14)

\begin{tabular}{|c|c|c|c|c|}
\hline Variável & Grupos & $\mathbf{N}$ & Média & Desvio padrão \\
\hline \multirow{2}{*}{ Ta } & MA1 & 32 & 42,38 & 9,94 \\
\hline & MA2 & 83 & 24,7 & 9,54 \\
\hline \multirow{2}{*}{$\mathrm{Tb}$} & MA1 & 32 & 44,19 & 10,41 \\
\hline & MA2 & 83 & 31,83 & 9,26 \\
\hline \multirow{2}{*}{ Tc } & MA1 & 32 & 13,44 & 6,32 \\
\hline & MA2 & 83 & 43,47 & 11,62 \\
\hline \multirow{2}{*}{ Cianita } & MIN1 & 70 & 7,49 & 5,56 \\
\hline & MIN2 & 45 & 8,65 & 7,98 \\
\hline \multirow{2}{*}{ Estaurolita } & MIN1 & 70 & 2,71 & 3,25 \\
\hline & MIN2 & 45 & 4,55 & 3,03 \\
\hline \multirow{2}{*}{ Andaluzita } & MIN1 & 70 & 1,72 & 1,67 \\
\hline & MIN2 & 45 & 3,03 & 3,35 \\
\hline \multirow{2}{*}{ Topázio } & MIN1 & 70 & 0,73 & 0,86 \\
\hline & MIN2 & 45 & 2,85 & 2,29 \\
\hline \multirow{2}{*}{ Anfibólio } & MIN1 & 70 & 0,79 & 2,13 \\
\hline & MIN2 & 45 & 0,35 & 0,78 \\
\hline \multirow{2}{*}{ Granada } & MIN1 & 70 & 0,32 & 0,42 \\
\hline & MIN2 & 45 & 0,14 & 0,19 \\
\hline \multirow{2}{*}{ Outros } & MIN1 & 70 & 0,71 & 2,61 \\
\hline & MIN2 & 45 & 0,95 & 2,04 \\
\hline \multirow{2}{*}{ Turmalina } & MIN1 & 70 & 16,77 & 9,31 \\
\hline & MIN2 & 45 & 33,44 & 10,35 \\
\hline \multirow{2}{*}{ Zircão } & MIN1 & 70 & 63,88 & 14,12 \\
\hline & MIN2 & 45 & 42,41 & 13,06 \\
\hline \multirow{2}{*}{ Rutilo } & MIN1 & 70 & 4,89 & 2,04 \\
\hline & MIN2 & 45 & 3,64 & 2,26 \\
\hline
\end{tabular}

Maior refinamento estratigráfico foi obtido com análises morfológicas de zircão e de turmalina. A análise morfológica do zircão foi eficaz para discriminar os Sedimentos Pós-Barreiras II (categorias arredondadas $=60 \%$ ) das demais unidades cenozoicas (categorias arredondadas - 50\%). É notável a eficácia da análise morfológica de turmalina para diferenciar as unidades cenozoicas entre si. O grau de arredondamento da turmalina aumenta em direção ao topo da sucessão cenozoica, com valores médios de $23 \%$ na Formação Barreiras, 40\% nos Sedimentos Pós-Barreiras I e 51\% nos Sedimentos Pós-Barreiras II. A capacidade de diferenciação estratigráfica das classes morfológicas de turmalina foi confirmada pela análise de agrupamento. As turmalinas mais arredondadas estão associadas aos Sedimentos Pós-Barreiras, o que revela o maior grau de retrabalhamento e o caráter policíclico desses estratos. Estatísticas descritivas e multivariadas evidenciam que o grau de arredondamento dos grãos é fator discriminante das unidades estudadas, com incremento de categorias arredondadas nas unidades mais jovens. Esse fato sugere que uma parte significativa das fontes de sedimentos para a Bacia Paraíba, durante o Cenozoico, foram rochas sedimentares preexistentes. $\mathrm{O}$ maior grau de retrabalhamento dos Sedimentos Pós-Barreiras, associado à sua similaridade composicional com a Formação Barreiras, aponta forte policiclismo na sucessáo cenozoica em estudo. Outro fator que colabora para o maior grau de arredondamento dos grãos na sucessóes quaternárias é a ação eólica e processos marinhos (Rossetti et al. 2011a, 2011b, 2012).

O índice ZTR é amplamente utilizado como parâmetro de maturidade, porém é de difícil interpretação. Apesar de incluir minerais de igual estabilidade química e física, estes têm diferenças significativas de densidade e podem ter fontes diferenciadas. Além disso, seu valor estatístico poderia ser questionado porque esse índice é calculado por meio da soma das percentagens de uma contagem geral dos principais minerais pesados. Neste estudo, foi observada uma variação pequena, porém progressiva, do ZTR, com aumento nas unidades mais jovens. Como o grau de arredondamento teve um aumento expressivo também nessa direção e os valores do índice de proveniência RZ mantiveram-se constantes, fica evidente a importância da contribuição de fontes sedimentares preexistentes. Pesquisadores anteriores (por exemplo, Coutinho \& Coimbra 1973, Gopinath et al. 1993) consideraram fonte principal dos depósitos sedimentares cenozoicos na área estudada a rochas da Província Borborema. Aqui não se descarta essa possibilidade. De fato, foram identificados pontos com anomalias de hornblenda, silliminita e cianita que sugerem contribuição direta das rochas cristalinas adjacentes (Lamus Ochoa 2010). Neste trabalho, ressalta-se que as fontes de sedimentos preexistentes tiveram uma significativa importância em detrimento à contribuição direta das rochas pré-cambrianas. 


\section{CONCLUSÕES}

Estatísticas descritivas e métodos de estatística multivariada revelaram semelhanças das porcentagens de minerais pesados da Formação Barreiras e Sedimentos Pós-Barreiras expostas no Estado da Paraíba, com impossibilidade de sua separação por meio da composição mineralógica. A avaliação estatística demonstra relação entre a granulometria e estratigrafia, com a maioria das amostras pelíticas associdas à Formação Barreiras e amostras relativamente mais arenosas relacionadas aos Sedimentos Pós-Barreiras I e II. Contudo, as análises morfológicas de zircão e de turmalina foram mais eficientes na diferenciação dessas unidades sedimentares, com incremento das categorias arredondadas de zircão e turmalina em direção às unidades mais jovens.

A análise estatística dos dados granulométricos, mineralógicos e de morfologia confirma que o grau de arredondamento dos gráos é fator discriminante da estratigrafia, com incremento de categorias arredondadas em unidades mais jovens. Esses resultados, somados ao aumento do ZTR também na direção das unidades mais jovens e à constância do índice de proveniência $\mathrm{RZi}$, sugerem que uma parte significativa das fontes de sedimentos para a Bacia Paraíba durante o Cenozoico foram rochas sedimentares preexistentes. Por outro lado, valores anomalamente altos de hornblenda, silliminita e cianita apontam que não se pode descartar a contribuição direta adicional de rochas cristalinas adjacentes para a sedimentação cenozoica.

\section{AGRADECIMENTOS}

Os autores agradecem o suporte financeiro da FAPESP (Projeto 06/04687-7). Os agradecimentos são estendidos à CAPES, pela concessão de bolsa de mestrado ao primeiro autor, e aos estudantes Victor Maurer, Caio Melo, Flávia Declout e Helena Andrade, pelo auxílio no processamento das amostras.

\section{REFERÊNCIAS}

Almeida F.F.M., Hasui Y., Brito Neves B.B., Fuck R.A. 1977. Províncias Estruturais Brasileiras. In: SBG, Simp. Geol. Nordeste, 8, Atas, p. 363-391.

Aitchison J. 1982. The statistical analysis of compositional data (with discussion). Journal of the Royal Statistical Society. 44(2):139-177.

Alheiros M.M. \& Lima Filho M. 1991. A Formação Barreiras, Estudos Geológicos, 10:77-88

Arai M. 2006. A grande elevação eustática do mioceno e sua influência na origem do Grupo Barreiras. Geologia USP-Série Científica, 6(2):1-6.

Barbosa J.A. 2004. Evolução da Bacia da Paraíba durante o Maastrichtiano-Paleoceno: formações Gramame e Maria Farinha, NE do Brasil. Dissertação de Mestrado, Universidade Federal de Pernambuco, Recife, $230 \mathrm{p}$.

Barbosa J.A. 2007. A deposição carbonática na faixa costeira recife-natal, NE do Brasil. Tese de Doutorado, Universidade Federal de Pernambuco, Recife, $270 \mathrm{p}$.

Barbosa J.A., Neumann V.H., Lima Filho M., Souza E.M., Moraes M.A. 2007. Estratigrafia da faixa costeira Recife-Natal (Bacia da Paraíba e Plataforma de Natal), NE Brasil. Estudos Geológicos, $17(2)$ : 3-30

Basu A. 1985. Influence of climate and relief on composition of sands released at source areas. In: Zuffa G.G. (ed.). Provenance of arenites. Dordrecht, D. Reidel Publishing Company, p.95-113.
Beurlen K. 1967. Estratigrafia da faixa sedimentar costeira Recife-João Pessoa. Boletim da Sociedade Brasileira de Geologia, 16(1):43-53.

Bezerra F.H.R., Neves B.B.B., Correa A.C.B., Barreto A.M.F., Suguio K. 2008. Late Pleistocene tectonic-geomorphological development within a passive margin - the Cariatá trough, northeastern Brazil. Geomorphology, 97:555-582.

Bigarella J.J. 1975. The Barreiras Group in Northeastern Brazil. Anais da Academia Brasileira de Ciências, 47(Supl):366-392.

Bigarella J.J. \& Andrade G.O. 1964. Considerações sobre a estratigrafia dos sedimentos cenozóicos em Pernambuco (Grupo Barreiras). Arquivos: Instituto de Ciências da Terra, 2:2-14.

Brito Neves B.B., Albuquerque J.P.T., Coutinho J.M.V, Bezera F.H.R. 2009. Novos dados geológicos e geofísicos para a caracterização geométrica e estratigráfica da Sub-bacia de Alhandra (Sudeste da Paraíba). Geologia USP, São Paulo, 9(2):63-87.

Brito Neves B.B., Santos E.J., Van Schmus W.R. 2000. The Tectonic History of the Borborema Province. In: Cordani U.G., Milani E.J., Thomaz Filho A., Campos D.A. (eds.). Tectonic evolution of the South American Continent, Rio de Janeiro, $38^{\text {th }}$ International Geological Congress, p.151-182.

Campos e Silva A. 1968. O Grupo Barreiras e unidades correlatas no Rio Grande do Norte. In: SBG, Simp. Geol. Nordeste, 4, Atas, p.21-22. 
Coutinho J.M.V. \& Coimbra A.M. 1973. Os pesados do Barreiras na costa Oriental Brasileira: Estudo de áreas-fonte. In: SBG, Congr. Bras. Geol., 28, Anais, p. 27-41.

Corfu F., Hanchar J. M., Hoskin P.W.O., Kinny P. 2003. Atlas of zircon textures. In: Hanchar J.M., Hoskin P.W.O. (eds.) Zircon: Reviews in mineralogy \& geochemistry. Washington, The Mineralogical Society of America, 53, p. 469-500.

Dantas J.R.A. 1982. Mapa geológico da Paraíba. Rio de Janeiro, Ministério de Minas e Energia. Departamento Nacional de Produção Mineral. Companhia de Desenvolvimento de Recursos Minerais da Paraíba, mapa, escala 1:500.000.

Dill H.G. 1998. A review of heavy minerals in clastic sediments with case studies from the alluvial-fan through the nearshoremarine environments. Earth-Science Reviews, 45:103-132.

Galehouse J.S. 1969. Counting grain mounts: number percentage vs number frequency. Journal of Sedimentary Petrology, 39(1-2):812-815.

Giannini P.C.F. Aguiar V.A. Sousa A.J. 2007. Momento-expansão (calcula e tabula parâmetros estatísticos de distribuição granulométrica pela técnica dos momentos de Pearson para lotes de até 200 amostras)

Gopinath T.R., Costa C.R.S., Sousa Júnior M.A. 1993. Minerais pesados e processos deposicionais dos sedimentos da Formação Barreiras, Paraíba In: SBG, Simp. Geol. do Nordeste, 15, Anais, p. 47-48.

Hubert J.F. 1962. A zircon-tourmaline-rutile maturity index and the interdependence of the composition of heavy mineral assemblages with the gross composition and texture of sandstones. Journal of Sedimentary Petrology, 32:440-450.

Kegel W. 1955. Geologia do fosfato de Pernambuco. Boletim da Divisão de Geologia e Mineralogia, Rio de Janeiro, DNPM/DFPM, Boletim 157, 54p.

Lamus Ochoa F. 2010. Análise de minerais pesados aplicada ao mapeamento geológico na Bacia Paraíba. Dissertação de Mestrado, Instituto de Geociências, Universidade de São Paulo, São Paulo, 186 p.

Lima Filho M.F. 1998. Análise estrutural e estratigráfica da Bacia Pernambuco. Tese de Doutorado, Instituto de Geociências, Universidade de São Paulo, São Paulo, 139 p.

Lima Filho M.F. \& Souza E.M. 2001. Marco estratigráfico em arenitos calcíferos do Campaniano da Bacia Paraíba: estratigrafia e significado paleoambiental. In: SBG Simp. Geol. Nordeste, 19, Anais, p. 87-88

Lima Filho M., Barbosa J.A., Souza E.M. 2006. Eventos tectônicos e sedimentares nas bacias de Pernambuco e da Paraíba: implicações no quebramento do Gondwana e correlação com a Bacia do Rio Muni. Geociências UNESP, 25(1):117-126.

Mabesoone J.M., Campos e Silva A., Beurlen K. 1972. Estratigrafia e origem do Grupo Barreiras em Pernambuco, Paraíba e Rio Grande do Norte. Revista Brasileira de Geociências, 2:173-188.

Mange M.A. \& Maurer H.F.W. 1992. Heavy minerals in colour. Champman \& Hall, London, 147 p.

Mange-Rajetzky M.A. 1995. Subdivision and correlation of monotonous sandstone sequences using high resolution heavy mineral analysis, a case study: the Triassic of Central Graben. In: Dunay R.E., Hailwood E.A. (eds.) Non-biostratigraphical methods of dating and correlation. London, Geological Society of London, 89 , p. 23-30
Mange M.A., Dewey J.F., Wright D.T. 2003. Heavy minerals solve structural and stratigraphic problems in Ordovician strata of the western Irish Caledonides. Geological Magazine, 140:25-30.

Mange M.A., Otvos E.G. 2005. Gulf coastal plain evolution in Wert Louisiana: Heavy mineral provenance and Pleistocene alluvial chronology. Sedimentary Geology, 182:29-57.

Magalhães M.N. \& Lima A.C.P. (eds.) 2002. Noções de Probabilidade e Estatística. Editora da Universidade de São Paulo, São Paulo, $392 \mathrm{p}$.

Mcmanus J. 1991. Grain size determination and interpretation. In: Tucker M.E. Techniques in sedimentology. Oxford, Blackwell, p. 63-85.

MINITAB INC. 2006. Minitab Statistical Software English version 15.

Morton A.C. 1991. Geochemical studies of detrital heavy minerals and their application to provenance research. In: Morton A.C., Tood S.P., Haughton P.D. (eds.) Developments in Sedimentary Provenance Studies. London, Geological Society of London, 57, p. 31-45.

Morton A.C., Todd S.P., Haugton P.D.W. 1991. Developments in sedimentary provenance studies. London, Geological Society of London, 370 p.

Morton A.C. \& Hallsworth C. 1994. Identifying provenancespecific features of detrital heavy mineral assemblages in sandstones. Sedimentary Geology, 90:241-256.

Morton A.C. \& Hurst A. 1995. Correlation of sandstones using heavy minerals: an example from the Statfjord Formation of the Snorre Field, northern North Sea. In: Dunay R.E. Hailwood E.A. (eds) Non-biostratigraphical methods of dating and correlation, London, Geological Society of London, 89, p. 3-22.

Morton A.C. \& Grant S. 1998. Cretaceous depositional systems in the Norwegian Sea: heavy minerals constraints. American Association of Petroleum Geologists Bulletin, 82:274-290.

Powers M.C. 1953. A new roundness scale for sedimentary particles. Journal of Sedimentary Petrology, 23:117-119.

Rossetti D.F. 2000. Influence of low amplitude/high frequency relative sea-level changes in a wave-dominated estuary (Miocene), São Luís Basin, northern Brazil. Sedimentary Geology, 133:295-324

Rossetti D.F. 2004. Paleosurfaces from northeastern Amazonia as a key for reconstructing paleolandscapes and understanding weathering products. Sedimentary Geology, 169:151-174.

Rossetti D.F. \& Góes A.M. 2001. Imaging Upper Tertiary to Quaternary deposits from northern Brazil applying ground penetrating radar. Revista Brasileira de Geologia, 31:195-202.

Rossetti D.F. \& Góes A.M. 2007. Deformação sin-sedimentar quaternária no nordeste do Brasil e sua implicação estratigráfica. In: Cong. ABEQUA, 11, CD ROM.

Rossetti D.F. \& Góes A.M. 2009. Marine influence in the Barreiras Formation, State of Alagoas, northeastern Brazil. Anais da Academia Brasileira de Ciências, 81:741-755.

Rossetti D.F., Góes A.M., Valeriano M.M. 2007. Correlação estratigráfica da "Formação Barreiras" no Nordeste e Norte do Brasil. In: Cong. ABEQUA, 11, CD ROM.

Rossetti D.F., Bezerra F.H.R., Brito Neves B.B., Góes A.M. 2011 a. Sediment deformation in Miocene and post-Miocene strata, Northeastern Brazil: Evidence for paleoseismicity in a passive margin. Sedimentary Geology, 235:172-187. 
Rossetti D.F., Bezerra F.H.R., Góes A.M., Valeriano M.M., AndradeFilho C.O., Mittani J.C.R., Tatumi S.H., Brito Neves B.B. 2011b . Late quaternary sedimentation in the Paraíba Basin, Northeastern Brazil: Landform, sea level and tectonics in Eastern South America passive margin. Palaeogeography, Palaeoclimatology, Palaeoecology, 300:191-204.

Rossetti D.F., Góes A.M., Bezerra F.H.R., Valeriano M.M., Brito Neves B.B., Lamus-Ochoa F. 2012. Refining the stratigraphy in onshore areas of the Paraíba Basin. Anais da Academia Brasileira de Ciências, 84:187-207.

Sá J.H.S. 1969. Contribuição à geologia dos sedimentos terciários e quaternários da Região Bragantina. Bol. Inst. Geol., 3:21-36.

Salim J., Souza C.J., Muniz G.C.B., Lima M.R. 1975. Novos subsídios para a elucidação do episódio "Barreiras" no Rio Grande do Norte. In: Simp. Geog., 7, Atas, p.149-158.

Shimabukuro S. \& Arai M. 1999. A transgressão marinha miocênica no Brasil: considerações baseadas no estudo do Grupo
Barreiras e da Formação Pirabas. Anais da Academia Brasileira de Ciências, 71(1):144.

Santos E.J., Ferreira C.A. Silva Júnior J.M. 2002. Geologia e Recursos Minerais do Estado da Paraíba. Recife, Ministério de Minas e Energia. Departamento Nacional de Produção Mineral, 2 mapas, escala 1:500.000.

Svendsen J.B. \& Hartley N.R. 2002. Synthetic heavy mineral stratigraphy: applications and limitations. Marine and Petroleum Geology, 19:389-405.

Van Schmus W.R., Oliveira E.P., Silva Filho A. F., Toteu S.F., Penaye J., Guimarães I.P. 2008. Proterozoic links between the Borborema Province, NE Brazil, and Central African Fold Belt. In: Pankhurst R.J., Trouw R.A.J., Brito Neves B.B., Wit M.J. (eds.) West Gondwana: Pre-Cenozoic correlations across the South Atlantic Region. London, Geological Society of London, p. 69-99.

Arquivo digital disponível on-line no site www.sbgeo.org.br 